\title{
Extractive Resolution of Racemic Mandelic Acid through a Bulk Liquid Membrane Containing Binary Chiral Carrier
}

\author{
Ling Yang, Xiao Qing Chen* and Fei Peng Jiao
}

\author{
School of Chemistry and Chemical Engineering, Central South University, Changsha, 410083, China
}

\begin{abstract}
Um método empregando "bulk liquid membrane" (BLM) e o complexo ácido di(2-etilhexil) fosfórico (D2EHPA) e ácido $O, O$ '-dibenzoil-(2R,3R)-tartárico ( $L$-(-)-DBTA) foi desenvolvido para a separação por extração do ácido mandélico racêmico ( $r a c$ MA). Os efeitos de tempo de resolução, concentração de D2EHPA na fase orgânica, concentração de rac MA na fase doadora, velocidade de agitação e temperatura sobre a separação por extração foram estudados. Os resultados experimentais evidenciaram que o maior fator de separação $(\alpha)$ 2,74 e o valor do excesso enantiomérico (ee, \% $46,47 \%$ foram obtidos quando o tempo de resolução foi de aproximadamente $4 \mathrm{~h}$, a razão de concentração molar de rac MA, D2EHPA e $L$-(-)-DBTA foi 0,05:0,2:0,3, a velocidade de agitação, $400 \mathrm{r} \mathrm{min}^{-1} \mathrm{e}$ a temperatura, $35^{\circ} \mathrm{C}$. O método desenvolvido é útil para a otimização do transporte de sistemas BLM e para a produção em grande escala de enantiômero puro.
\end{abstract}

A method of bulk liquid membrane (BLM) using complex of di(2-ethylhexyl) phosphoric acid (D2EHPA) and $O, O^{\prime}$-dibenzoyl-( $\left.2 R, 3 R\right)$-tartaric acid ( $L$-(-)-DBTA) was developed for the extractive resolution of racemic mandelic acid ( $r a c$ MA). The effects of resolution time, concentration of D2EHPA in the organic phase, concentration of rac MA in the feed phase, stirring speed and temperature on extractive resolution were studied. The experimental results have shown that the greatest separation factor $(\alpha) 2.74$ and the enantiomeric excess value $(e e, \%) 46.47 \%$ were obtained when the resolution time was about $4 \mathrm{~h}$, the molar concentration ratio of rac MA, D2EHPA and $L$-(-)-DBTA 0.05:0.2:0.3, the stirring speed $400 \mathrm{r} \mathrm{min}^{-1}$ and the temperature $35^{\circ} \mathrm{C}$. The developed method is helpful for optimizing the transport of BLM systems and for large-scale production of pure enantiomer.

Keywords: D2EHPA, L-(-)-DBTA, bulk liquid membrane, extraction resolution, mandelic acid

\section{Introduction}

The production of single-enantiomer drugs is one of the hot-topics in the world. ${ }^{1-3}$ Extractive separation of liquid membrane, a new type of extractive separation technology, ${ }^{4}$ originated in the 1960's is widely used in chiral separation process ${ }^{5,6}$ due to their cost effectiveness, low energy demand, set-up simplicity and the possibility to be used in continuous mode. Bulk liquid membrane (BLM) is one of the types of liquid membranes. In a BLM, a relatively thick layer of immiscible fluid is used to separate the feed and strip phases. There is no means of support for the membrane phase and it is kept apart from the external phases only by means of its immiscibility. A recent development of chiral resolution in bulk liquid membranes is the incorporation of single enantioselective carrier within

*e-mail: xqchen@mail.csu.edu.cn the liquid membrane phase, chemically facilitating the transport of a specific compound across the membrane..$^{7-11}$ However, the enantioselectivity of the single carrier is somehow low, therefore the use of binary chiral carrier was introduced while looking for new unitary chiral carrier with high separation capacity and large separation scale. Binary chiral carrier ${ }^{12}$ is the complexation of two kinds of carriers and produces coordinated effect, they generate complementary action to obtain high chiral separation effect because of their different characteristics and ways of action. Tan et al. ${ }^{13}$ introduced the complex of D2EHPA and tartaric acid derivatives as a new binary chiral carrier for the separation of $r a c$ amino acids by extraction, which showed good enantioselectivity and a high distribution ratio.

$L$-(-)-DBTA (Figure 1) has been known as a chiral selector of enantiomers, such as ephedrine, chiral alcohols, ${ }^{14}$ $\mathrm{N}$-methylamphetamine ${ }^{15}$ and amino acids. ${ }^{13}$ Although $L$-(-)-DBTA has the ability to resolute enantiomers, the 
enantioselectivity is still relatively low, especially its extraction capacity is also very low. These performances are not helpful to the industrial application. The cationic carrier D2EHPA (Figure 1) has been reported to be one of the most promising carriers for liquid membrane formulation. ${ }^{16,17}$ Particular advantages of D2EHPA are its chemical stability, high complexing ability, extremely low solubility in aqueous solutions, versatility and high extraction capacity ${ }^{17}$ in the extraction of many amino acids, and its availability in commercial quantities.<smiles>O=C(O)C(O)c1ccccc1</smiles>

MA

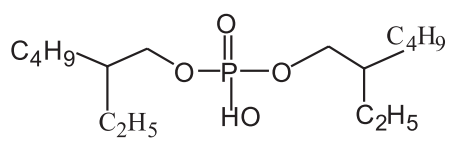

D2EHPA

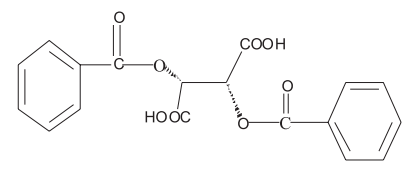

$L-(-)-D B T A$

Figure 1. Structure of MA, D2EHPA, $L$-(-)-DBTA.

Mandelic acid (MA) is a chiral molecule and its two single enantiomers have a significant difference in pharmacological effects. It is a intermediate, which is used to synthesize vasodilator cyclandelate, urinary tract disinfectant urotropine, etc. ${ }^{18,19}$ Extraction techniques have been used for the resolution of $d, l$-MA. ${ }^{20} \alpha$-Cyclohexyl-mandelic acid, a derivative of MA, also has been studied by extraction. ${ }^{21}$ But a single chiral selector is generally used for the resolution of MA and its derivatives, the enantioselectivity of these selectors are somehow low. ${ }^{21}$ Based on the previous works, this paper investigated the extractive resolution of racemic MA (Figure 1), through a BLM by the complex of D2EHPA and $L$-(-)-DBTA as the binary chiral carrier, and tried to obtain the optimal conditions of extractive resolution. So far, this is the first use of binary chiral carrier in the field of extraction resolution of rac MA by BLM. The results may be extrapolated for realizing large-scale application of chiral resolution through the BLM.

\section{Experimental}

\section{Chemicals}

$R a c$ MA and $L$-phenylalanine were purchased from Guangfu Institute of Fine Chemicals (Tianjin, China). $\mathrm{CuSO}_{4} \cdot 5 \mathrm{H}_{2} \mathrm{O}$ was obtained from Kemiou chemical reagents
Co. Ltd (Tianjin, China). D2EHPA was supplied by Chemical reagent Sinopharm Group Co.Ltd (Shanghai, China). $L$-(-)-DBTA with a purity $>99 \%$ was obtained from Lingxing \& Co.Inc. (Zhejiang, China). $n$-Octanol was produced by Lingfeng Chemical reagent Co. Ltd (Shanghai, China). All other chemicals were of analytical reagent grade.

\section{Analytical method}

The quantification of MA in the aqueous phase was performed by HPLC using a UV detector (Shimadzu, Japan). The column was Lichrospher $\mathrm{C}_{18}, 5 \mu \mathrm{m}$ particle size of the packing material, $250 \mathrm{~mm} \times 4.6 \mathrm{~mm}$ I.D. (Hanbon Sci. Technol. Co. Ltd, China). The mobile phase for MA enantiomers was $3 \mathrm{mmol} \mathrm{L}^{-1} \mathrm{CuSO}_{4}$ and $6 \mathrm{mmol} \mathrm{L}^{-1}$ $L$-phenylalanine aqueous solution : methanol $(85: 15, \mathrm{v} / \mathrm{v})$ at a flow rate of $0.6 \mathrm{~mL} \mathrm{~min}^{-1}$, the UV spectrophotometer was operated at $300 \mathrm{~nm}$, the column temperature was kept at $30{ }^{\circ} \mathrm{C}$. The retention time of the $(D)$-enantiomer is lower than that of the $(L)$-enantiomer (Figure 2).
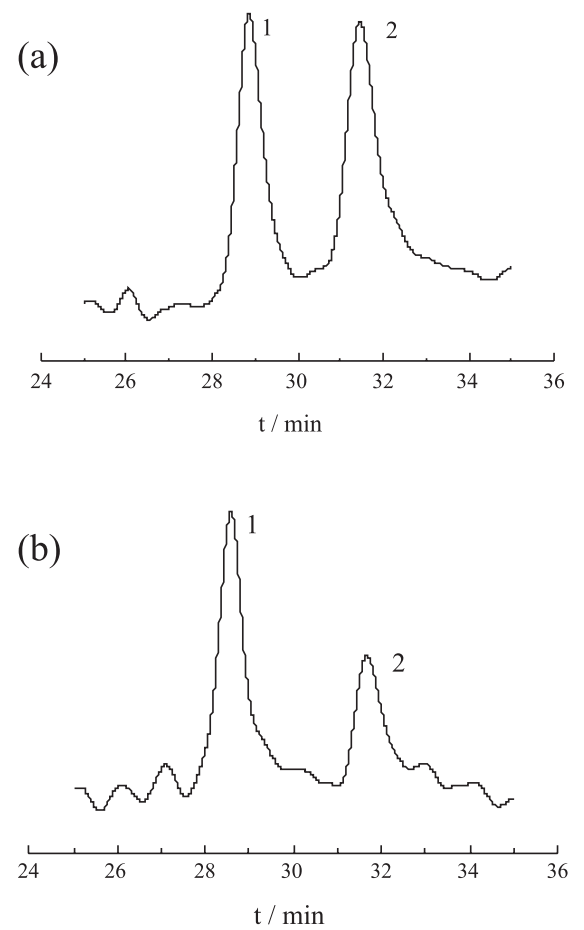

Figure 2. HPLC chromatogram of mandelic acid enantiomers. 1: $D$-mandelic acid; 2: $L$-mandelic acid. (a) Before separation: aqueous solution, $30{ }^{\circ} \mathrm{C}$. (b) After separation: strip phase solution, $30^{\circ} \mathrm{C}$, concentration ratio of MA, D2EHPA and L-(-)-DBTA of $0.05: 0.2: 0.3,4 \mathrm{~h}, 400 \mathrm{r} \mathrm{min}^{-1}$.

\section{Procedure for the enantioselective transport}

The experimental studies were carried out applying the BLM technique (Figure 3). The left aqueous feed 
solution (50 mL) consisted of MA aqueous with different concentration. The strip solution $(50 \mathrm{~mL})$, which consisted of deionized water, was located in the right part of the vessel. The organic membrane phase $(100 \mathrm{~mL})$, prepared by dissolving $L-(-)$-DBTA and D2EHPA with different concentration ratio in $n$-octanol, was added above of the aqueous phases. The contact area between the feed phase and membrane and the membrane and strip phase of the single BLM system were all $12.56 \mathrm{~cm}^{2}$. The experiments were carried out at $30^{\circ} \mathrm{C}$ by using a thermostated apparatus. The feed solution and the strip solution were stirred at $400 \mathrm{r} \mathrm{min}^{-1}$. The process of enantioselective transport is shown in Figure 4. In each experiment, $10 \mu \mathrm{L}$ sample was withdrawn at fixed interval time from the feed phase and strip phase in order to allow the HPLC analysis.

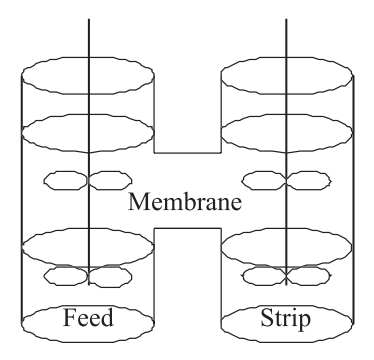

Figure 3. Transport cell of bulk liquid membrane.

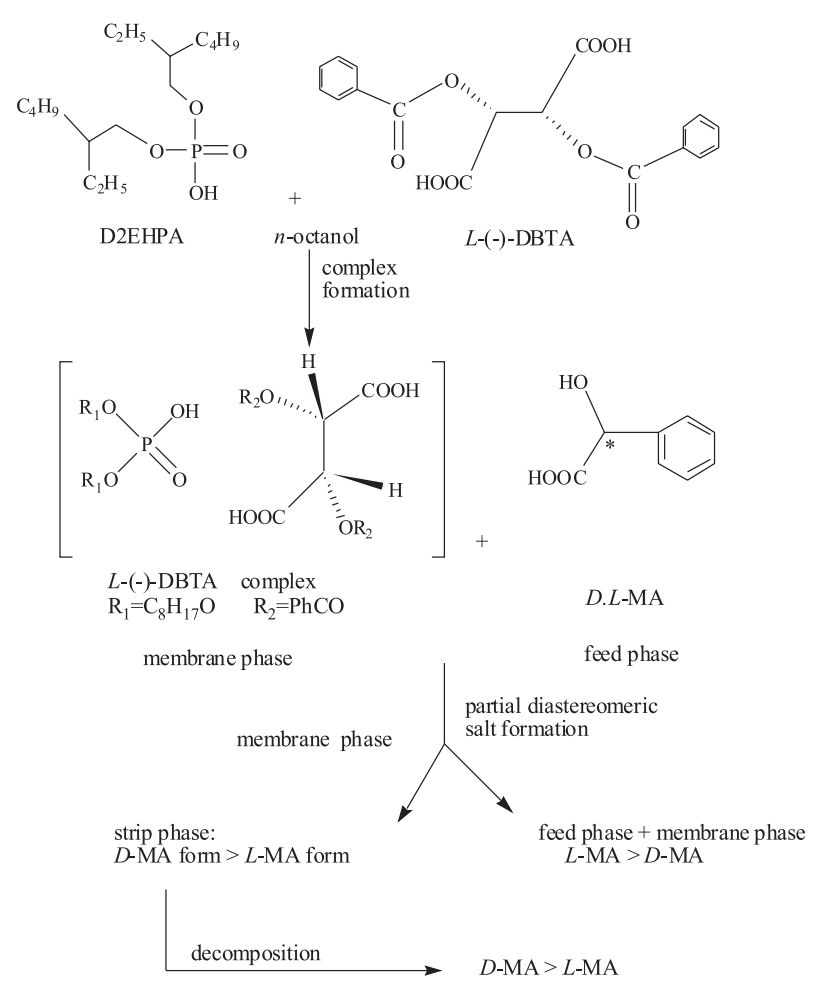

Figure 4. The enantioselective transport process.

The average flux ( $\mathbf{J}$ ) of each enantiomer was calculated by equation 1 , the enantioselectivity was calculated by equations 2 and 3 in terms of the separation factor $(\alpha)$ and the percentage enantiomeric excess $(e e, \%)$ :

$\mathrm{J}=\frac{\mathrm{V}_{\mathrm{S}} \Delta \mathrm{C}_{\mathrm{S}}}{\mathrm{At}}$

$\alpha=\frac{\mathrm{J}_{\mathrm{d}}}{\mathrm{J}_{1}}$

ee, $\%=\frac{\mathrm{J}_{\mathrm{d}}-\mathrm{J}_{1}}{\mathrm{~J}_{1}+\mathrm{J}_{\mathrm{d}}} \times 100$

where $\mathrm{t}$ is the time of resolution, $\Delta \mathrm{Cs}$, is measured in the strip, Vs the volume of the strip solution and A the effective membrane area. This is the average flux from the start of the experiment till time $t$.

\section{Results and Discussion}

\section{Effect of resolution time}

Using $26.28 \mathrm{mmol} \mathrm{L}^{-1} \mathrm{MA}$ in feed phase, $0.2 \mathrm{~mol} \mathrm{~L}^{-1}$ D2EHPA and $0.3 \mathrm{~mol} \mathrm{~L}^{-1} L$-(-)-DBTA in organic phase, the effect of resolution time on flux and enantioselectivity was studied at $30{ }^{\circ} \mathrm{C}$, keeping stirring speed $400 \mathrm{r} \mathrm{min}^{-1}$. Figure $5 \mathrm{a}$ shows that flux of each enantiomer increases with the increasing time at the initial stage, then after $5.5 \mathrm{~h}$ $\mathrm{J}_{1}$ still increase slowly while $\mathrm{J}_{\mathrm{d}}$ begins to decrease. The possible reason is that the chiral carrier in organic phase prefers combining with $D$-(+)-MA and then transports it from the feed phase to the strip phase. Therefore, the time of maximum $\mathrm{J}_{\mathrm{d}}$ occurs before than that of maximum $\mathrm{J}_{\mathrm{l}}$, then $\mathrm{J}_{\mathrm{d}}$ decreases with the decreasing concentration gradient between feed and strip phases. It can be seen in Figure $5 \mathrm{~b}$ that $\alpha$ and $e e, \%$ have similar patterns, i.e. both reach maxima of 1.94 and $31.95 \%$, respectively, at $4 \mathrm{~h}$, thenceforth declining all along till the equilibrium.

\section{Effect of D2EHPA concentration in membrane phase}

The effect of various D2EHPA concentrations on flux and enantioselectivity was investigated under the same conditions as above except that analytical sampling undergoes $4 \mathrm{~h}$ from the beginning. Figure 6a shows that the flux of enantiomer monomer decreases with the increasing D2EHPA concentrations, and reaches minimum at $0.2 \mathrm{~mol} \mathrm{~L}^{-1}$ (D2EHPA concentration), then increases with the increase of D2EHPA concentrations. As the complexes which D2EHPA forms with $L$-(-)-DBTA at low concentrations only improve the enantioselectivity to enantiomer, with increasing D2EHPA concentration, excessive D2EHPA reacts on extraction and accordingly 
(a)

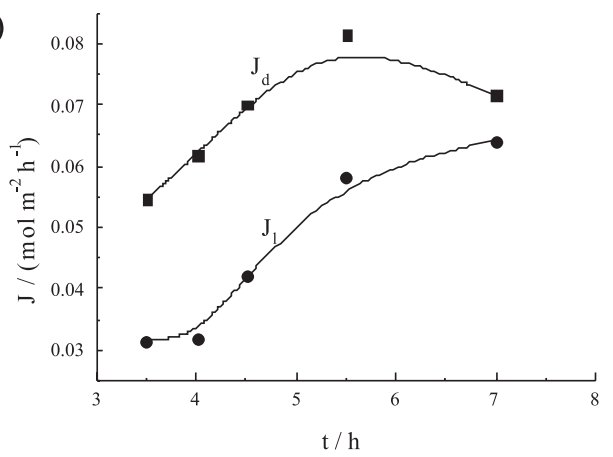

(b)

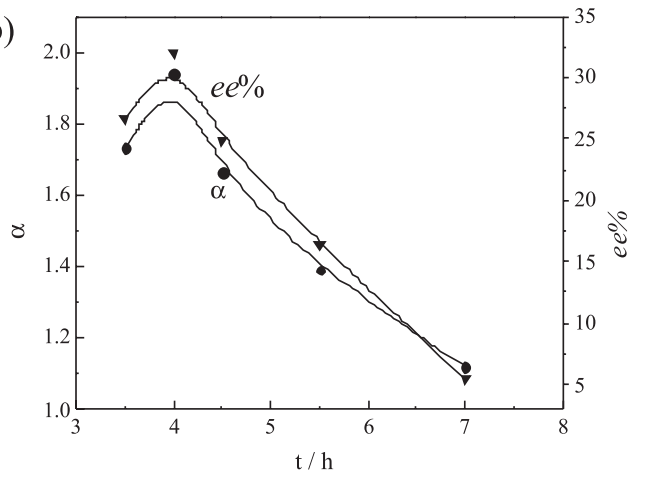

Figure 5. (a) Effect of time on flow J. (b) Effect of time on enantioselectivity for MA.

speed up the transport of enantiomer monomer. Figure $6 \mathrm{~b}$ shows that, the enantioselectivity of $L$-(-)-DBTA increases with the increase of D2EHPA concentrations up to $0.2 \mathrm{~mol} \mathrm{~L}^{-1}$ and then decreases with the increase of D2EHPA concentration. As D2EHPA is a type of acidic phosphoric extraction solvent without any enantioselectivity, excessive D2EHPA only reacts on extraction, yet reduces the ennatioselectivity of chiral carrier. Therefore, with $\mathrm{C}_{\text {D2EHPA }}: \mathrm{C}_{\mathrm{DBTA}}=2: 3$, the formed complex has the best enantioselectivity.

\section{Effect of MA concentration}

The effect of MA concentration on resolution was investigated under the same conditions as adopted for the effect of resolution time, except that analytical sampling undergoes $4 \mathrm{~h}$ from the beginning. As shown in Figure 7, the flux of enantiomeric monomer increases with the increase of MA concentration, however, $\alpha$ and $e e, \%$ increase with the increasing MA concentration up to $52.56 \mathrm{mmol} \mathrm{L}^{-1}$, and then decrease with the increase of MA concentration. As $J_{d}$ and $J_{1}$ both increase with the increasing MA concentration, and $\mathrm{J}_{1}$ increases faster than $J_{d}$ does, which results in the ratio of them, $\alpha$ getting smaller and smaller. Therefore, with $\mathrm{C}_{\text {MA }}: \mathrm{C}_{\text {D2EHРA }}: \mathrm{C}_{\text {DBTA }}=0.05: 0.2: 0.3$, the generated complex has the best enantioselectivity to rac MA. (a)

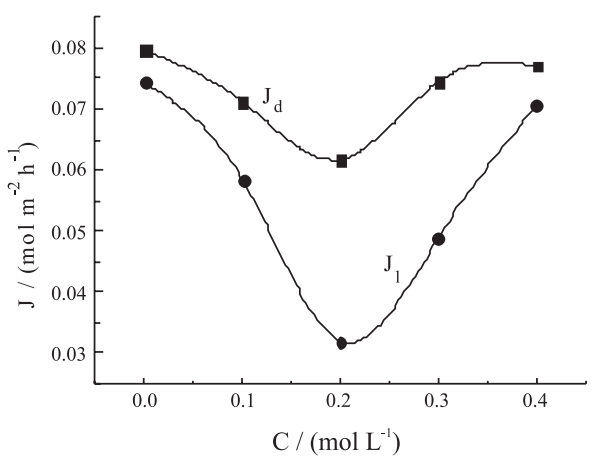

(b)

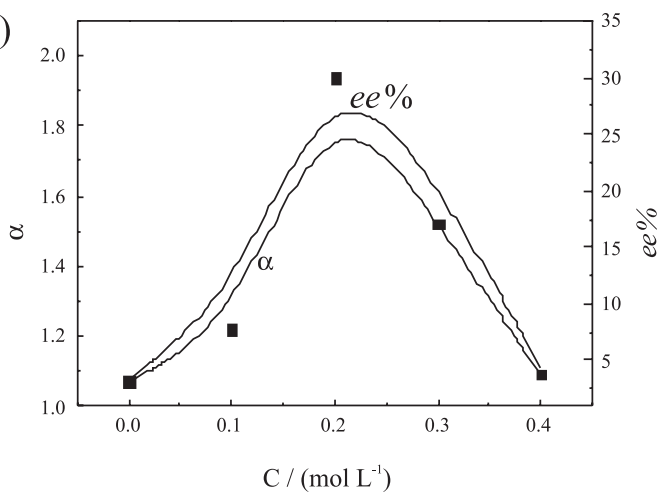

Figure 6. (a) Effect of concentration of D2EHPA in the organic phase on flow J. (b) Effect of concentration of D2EHPA in the organic phase on enantioselectivity for MA.

(a)

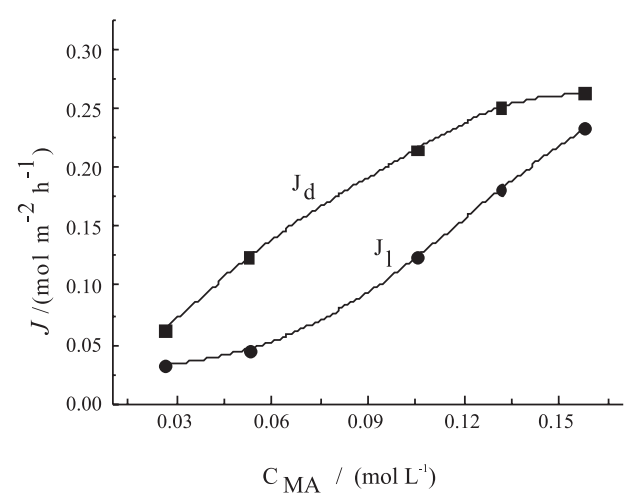

(b)

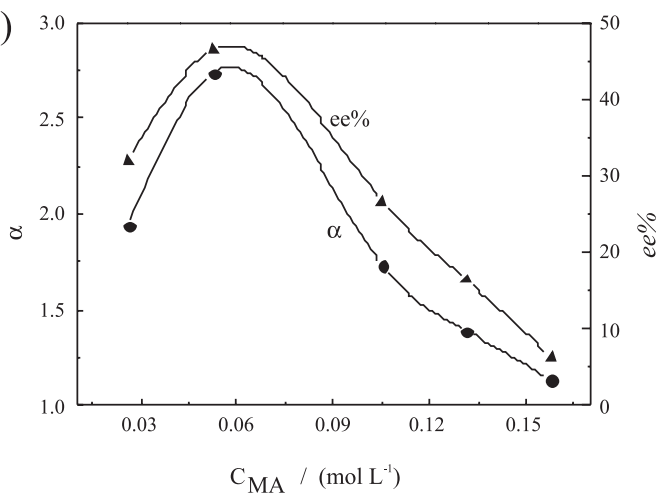

Figure 7. (a) Effect of concentration of MA in the feeding phase on flow J. (b) Effect of concentration of MA in the feeding phase on enantioselectivity for MA. 


\section{Effect of stirring speed}

Taking into account the effect of MA concentration, the best resolution result was obtained with MA concentration of $52.56 \mathrm{mmol} \mathrm{L}^{-1}$. The effect of stirring speed on flux and enantioselectivity was investigated under the same conditions as adopted for resolution time, except that analytical sampling undergoes $4 \mathrm{~h}$ from the beginning and the MA concentration $52.56 \mathrm{mmol} \mathrm{L}^{-1}$. As shown in Figure $8 \mathrm{a}$, the fluxes of two enantiomeric monomers increased with the increase of stirring speed and presented the greatest difference at $400 \mathrm{r} \mathrm{min}^{-1}$. It is consistent with the result of Figure 8b, at which $\alpha$ and $e e, \%$ reached maximum at $400 \mathrm{r} \mathrm{min}^{-1}$. However, with further increase of stirring speed to $500 \mathrm{r} \mathrm{min}^{-1}$, the feeding, membrane and stripping phases were mixed which lead to erratical variation of enantioselectivity.

(a)

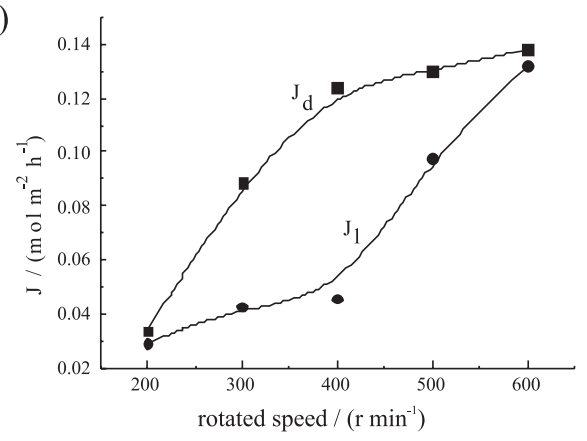

(b)

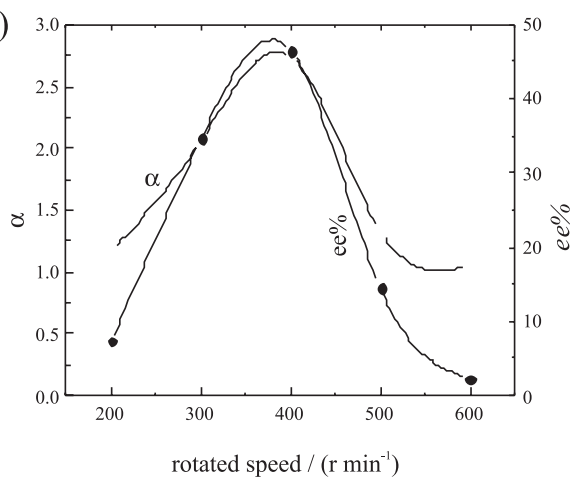

Figure 8. (a) Effect of rotation speed on flow J. (b) Effect of rotation speed on enantioselectivity for MA.

\section{Effect of temperature}

By fixing the MA concentration in $52.56 \mathrm{mmol} \mathrm{L}^{-1}$, the effect of temperature on flux and enantioselectivity was investigated under the same conditions as adopted for resolution time, except that analytical sampling undergoes $4 \mathrm{~h}$ from the beginning. As shown in Figure 9, the flux and enantioselectivity of enantiomer increases with the increasing temperature up to $35{ }^{\circ} \mathrm{C}$, and then decrease, which may be related to the stability of the complex formed by D2EHPA and $L$-(-)-DBTA. The higher temperature of BLM system could influence the stability of chiral carrier.

(a)

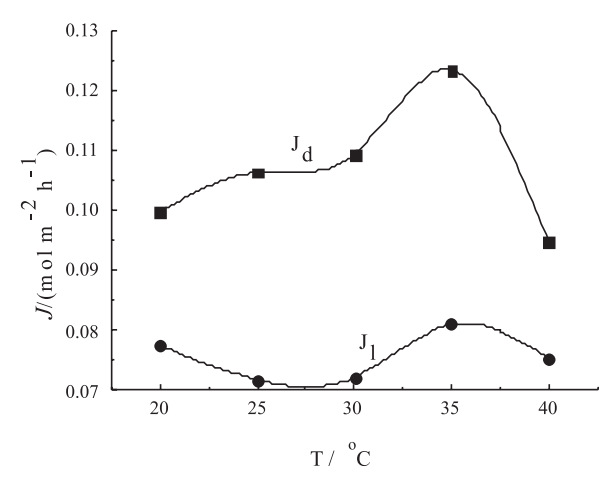

(b)

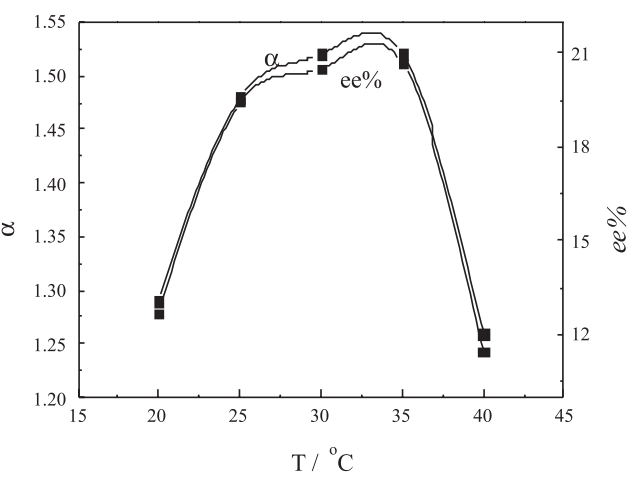

Figure 9. (a) Effect of temperature on flow J. (b) Effect of temperature on enantioselectivity for MA.

\section{Conclusions}

A complex of D2EHPA and $L$-(-)-DBTA was found to be a useful chiral carrier for the extractive resolution of $\mathrm{rac}$ MA in a BLM transport system. The enantioselectivity of $L$-(-)-DBTA is somehow low, and D2EHPA has no chiral resolution ability. But the enantioselectivity is greatly improved through the formation of a new complex by $L$-(-)-DBTA with D2EHPA. It was found that the optimal extractive resolution conditions were the separation time of $4 \mathrm{~h}$, concentration ratio of MA, D2EHPA to $L$-(-)-DBTA of 0.05:0.2:0.3, stirring speed at $400 \mathrm{r} \mathrm{min}^{-1}$ and temperature of the BLM system kept at $35^{\circ} \mathrm{C}$. Adopting these conditions, a separation factor of 2.74 and an enantiomeric excess value of $46.47 \%$ were obtained. The enantioselectivity was appreciably improved using binary chiral carrier in BLM, compared to single chiral carrier in BLM.

\section{Acknowledgments}

This work was supported by the Natural Science Foundation of China (20805058). 


\section{References}

1. Michael, J.; Chem. Ind. 1996, 53, 74.

2. Subramanian G.; Chiral Separation Techniques, Wiley-VCH, Verlag GmbH: Weinheim, 2001.

3. Jiao, F. P.; Huang, K. L.; Ning, F. R.; Hu, W. G.; Yu, J. G.; Sep. Sci. Technol. 2006, 41, 1893.

4. Wang, J. D.; Chen, J. Y; Solvent Extraction Handbook, $1^{\text {st }}$ ed., Chemical Industry Press: Beijing, China, 2001.

5. Way, J. D.; Noble, R. D.; Flynn, T. M; J. Membr. Sci. 1982, 12, 239.

6. León, G.; Guzmán, M. A.; Desalination 2005, 184, 79.

7. Marek, P.; Malgorzata, K.; Oksana, P.; J. Membr. Sci. 1998, $138,109$.

8. Henning, M. K.; Jeanette, L.; Klaas, K.; Jaco, C. B.; J. Membr. Sci. 2000, 167, 33.

9. Ma, M.; Chen, B.; Luo, X. B.; Tan, H.; He, D. S.; Xie, Q. J.;Yao, S. Z.; J. Membr. Sci. 2004, 234, 101.

10. Jiao, F. P.; Chen, X. Q.; Hu, W. G.; Yang, L.; Huang, K. L.; J. Braz. Chem. Soc. 2007, 18, 804.
11. Jiao, F. P.; Chen, X.Q.; Wang, Z.; Hu, Y. H.; Lat. Am. Appl. Res. 2008, 38, 267.

12. Pavel, A.. Levkin.; Volker, Schurig.; J. Chromatogr., A 2008 , 1184, 309.

13. Tan, B.; Luo, G. S.; Qi, X.; Wang, J. D.; Sep. Purif. Technol. 2006, 49, 186.

14. Kassai, C.; Juvancz, Z.; BaÂlint, J.; Fogassy, E.; Kozma, D.; Tetrahedron 2000, 56, 8355.

15. Nemák, K.; Acs, M.; Jászay, Z.M.; Kozma, D.; Fogassy, E.; Tetrahedron 1996, 52, 1637.

16. Hong, S.A.; Yang, J.W.; J. Membr. Sci. 1994, 86,181.

17. Teramoto, M.; Yamashiro, T.; Inoue, A.; J. Membr. Sci. 1991, $58,11$.

18. Choi, W. J.; Lee, K. Y.; Kanga, S. H.; Sep. Purif. Technol. 2007, $53,178$.

19. Yadav, G. D.; Sivakumar, P; Biochem. Eng. J. 2004, 19, 101.

20. Tang, K. W.; Chen, Y. Y.; Huang, K. L.; Tetrahedron: Asymmetry 2007, 18, 2399.

21. Zhou, D; Tang, K. W.; Liu, J. J.; J. Instrum. Anal. (China) 2006, 25,49 . 